\title{
Abaloparatide is an Effective Treatment Option for Postmenopausal Osteoporosis: Review of the Number Needed to Treat Compared with Teriparatide
}

\author{
Jean-Yves Reginster ${ }^{1} \cdot$ Gary Hattersley $^{2} \cdot$ Gregory C. Williams $^{2} \cdot$ Ming-yi Hu$^{2} \cdot$ Lorraine A. Fitzpatrick $^{2}$. \\ E. Michael Lewiecki ${ }^{3}$
}

Received: 16 May 2018 / Accepted: 22 June 2018 / Published online: 27 June 2018

(c) The Author(s) 2018

\begin{abstract}
Abaloparatide (ABL) is a 34-amino acid peptide designed to be a selective activator of the parathyroid hormone receptor type 1 signaling pathway. In the Abaloparatide Comparator Trial In Vertebral Endpoints (ACTIVE), subcutaneous ABL reduced the risk of new vertebral, nonvertebral, clinical, and major osteoporotic fracture compared with placebo and of major osteoporotic fracture compared with teriparatide. To further evaluate the effectiveness of ABL, we calculated the number needed to treat (NNT) to prevent one fracture using ACTIVE data. To estimate the potential effectiveness of ABL in populations at higher fracture risk than in ACTIVE, we calculated NNT for vertebral fracture using reference populations from historical placebo-controlled trials, assuming an $86 \%$ relative risk reduction in vertebral fracture with ABL treatment as observed in ACTIVE. NNT was calculated as the reciprocal of the absolute risk reduction in ACTIVE. The projected NNT for ABL in other populations was calculated based on incidence rate (IR) for vertebral fractures in the placebo arms of the FREEDOM (placebo IR 7.2\%), FIT-1 (placebo IR 15.0\%), and FIT-2 (placebo IR 3.8\%) trials. NNT for ABL in ACTIVE was 28 for vertebral, 55 for nonvertebral, 37 for clinical, and 34 for major osteoporotic fracture. NNT for these fracture types for teriparatide in ACTIVE were 30, 92, 59, and 75, respectively. Using placebo IRs from FREEDOM, FIT-1, and FIT-2, projected NNTs for vertebral fracture with ABL were 17,8, and 31. These data are useful for further evaluating ABL for the treatment of osteoporosis in postmenopausal women.
\end{abstract}

Keywords Postmenopausal osteoporosis $\cdot$ Abaloparatide $\cdot$ Number needed to treat $\cdot$ ACTIVE trial $\cdot$ Fracture risk reduction

\section{Introduction}

Abaloparatide (ABL) is a 34-amino acid peptide designed to be a selective activator of the parathyroid hormone receptor type 1 (PTHR1) signaling pathway. ABL binds selectively to the $\mathrm{RG}$ versus $\mathrm{R}^{0}$ conformation of PTHR1 [1], consistent with a net anabolic effect in contrast with PTH [2]. Preclinical and clinical studies of ABL resulted in increases in

Gary Hattersley

ghattersley@radiuspharm.com

1 Université de Liège, Place du 20-Août, 7, 4000 Liège, Belgium

2 Radius Health, Inc., 950 Winter St, Waltham, MA 02451, USA

3 New Mexico Clinical Research \& Osteoporosis Center, Inc., 300 Oak St, SE, Albuquerque, NM 87106, USA bone mass and bone mineral density (BMD), restoration of bone microarchitecture, and increased bone strength with no adverse effects on bone quality and no apparent concerns regarding bone safety [3-8].

In the 18-month phase 3 Abaloparatide Comparator Trial In Vertebral Endpoints (ACTIVE, NCT01343004), treatment with subcutaneously administered ABL for 18 months significantly increased BMD and decreased the risk of vertebral, nonvertebral, clinical, and major osteoporotic fractures compared with placebo. ACTIVE included an open-label teriparatide (TPTD) arm, and ABL significantly increased BMD at nonvertebral sites and significantly decreased the risk of major osteoporotic fractures compared with TPTD [5].

To further elucidate the effectiveness of $\mathrm{ABL}$, we evaluated the number needed to treat (NNT) to prevent one fracture (vertebral, nonvertebral, clinical, and major osteoporotic) using data from ACTIVE. To understand the 
potential effectiveness of $\mathrm{ABL}$ in patient populations at greater risk of fracture and with varying treatment durations, we also estimated the NNT for ABL using reference populations from historical placebo-controlled trials of treatments for postmenopausal women with osteoporosis.

\section{Methods}

\section{Study Patients and Treatments}

ACTIVE was a multicenter, multinational study that enrolled postmenopausal women (aged 49-86 years) who had osteoporosis. Eligibility criteria have been described in detail [5]. Briefly, osteoporosis was defined as having prior radiographic evidence of vertebral fracture or low-trauma nonvertebral fracture within 5 years of study enrollment and a T-score $\leq-2.5$ and $>-5.0$ at the lumbar spine or femoral neck for women aged $\leq 65$ years or a T-score $\leq-2.0$ at those same sites for women aged $>65$ years. For women older than 65 years, there was no prior fracture requirement if the lumbar spine or femoral neck T-score was $\leq-3.0$ and $>-5.0$. Eligible women were randomized 1:1:1 to receive either blinded ABL $80 \mu \mathrm{g} / \mathrm{d}$ or matching placebo or open-label subcutaneous injections of TPTD $20 \mu \mathrm{g} / \mathrm{d}$ for 18 months. The intent-to-treat population included 2463 patients, all of whom received supplementary calcium and vitamin D.

\section{NNT Calculations}

NNT to prevent one additional fracture (vertebral, nonvertebral, clinical, major osteoporotic) was calculated as the reciprocal of the absolute risk reduction (ARR) between the ABL and placebo groups and between the TPTD and placebo groups [9].

To project the potential effectiveness of ABL in other patient populations with different baseline levels of fracture risk than that in ACTIVE, we estimated the NNT for ABL in such populations by applying the $86 \%$ relative risk reduction (RRR) of vertebral fractures observed with ABL compared with placebo in ACTIVE to placebo incidence rates (IR) reported in historical reference populations. These reference populations included the Fracture Reduction Evaluation of Denosumab in Osteoporosis Every 6 Months trial (FREEDOM; denosumab vs. placebo for 3 years; placebo IR $=7.2 \%$ ) [10]; the Fracture Intervention Trial-1 (FIT-1; alendronate vs. placebo for 3 years; placebo $I R=15.0 \%)$ [11]; and the Fracture Intervention Trial-2 (FIT-2; alendronate vs. placebo for 4 years; placebo $\mathrm{IR}=3.8 \%$ ) [12].

\section{Results}

Fracture incidence rates for placebo, ABL, and TPTD following 18 months of treatment on ACTIVE [5] are displayed in Table 1 . The NNT values after 18 months of treatment with ABL or TPTD in ACTIVE are presented in Fig. 1. The NNT for new vertebral fractures was 28 for ABL and 30 for TPTD. The NNT for nonvertebral, clinical, and major osteoporotic fractures were 55 and 92, 37 and 59, and 34 and 75, for ABL and TPTD, respectively.

Projected NNTs for vertebral fractures based on placebo IRs reported in historical study populations are described in Fig. 2. Applying an $86 \%$ RRR in vertebral fracture to a placebo population with a $4 \%$ IR of new vertebral fracture, as seen in FIT-2 [12], yielded a projected NNT of 31 for ABL, while applying an $86 \%$ RRR to a placebo population with a 7\% IR, as seen in FREEDOM [10], yielded a projected NNT of 17 for ABL. Finally, applying an 86\% RRR in vertebral fracture to a placebo population with a $15 \%$ IR of new vertebral fracture, as seen in FIT-1 [11], yielded a projected NNT of 8 for ABL.

\section{Discussion}

The NNT is the reciprocal of the ARR and is expressed as a single value, representing the number of patients who must be treated to prevent one event of interest [9]. As discussed by Cranney et al., NNT is one way of describing the absolute impact of treatment [13], and the NNT for osteoporosis therapy can be considered by clinicians when making recommendations to patients and when making comparisons of cost effectiveness.

During ACTIVE, ABL reduced the risk of vertebral, nonvertebral, major osteoporotic, and clinical fractures compared with placebo and reduced the risk of major osteoporotic fractures compared with TPTD [5]. There was a consistent fracture risk reduction across a variety of baseline risk factors, including age groups ( $<65$ vs. 65 to $<75$ vs. $\geq 75$ years) in ACTIVE $[14,15]$.

The analyses described here show that following 18 months of treatment in ACTIVE, the NNT for ABL versus placebo was lower than that of TPTD versus placebo for multiple fracture endpoints. The NNT for ABL and TPTD in ACTIVE were similar for new vertebral fractures: 28 for ABL; 30 for TPTD. Additional fracture types beyond new vertebral fractures of course contribute significantly to disease burden and are of clinical interest when evaluating treatments for osteoporosis [16]. In this analysis, there was considerable divergence in the NNT between ABL and TPTD for other fracture types, with 


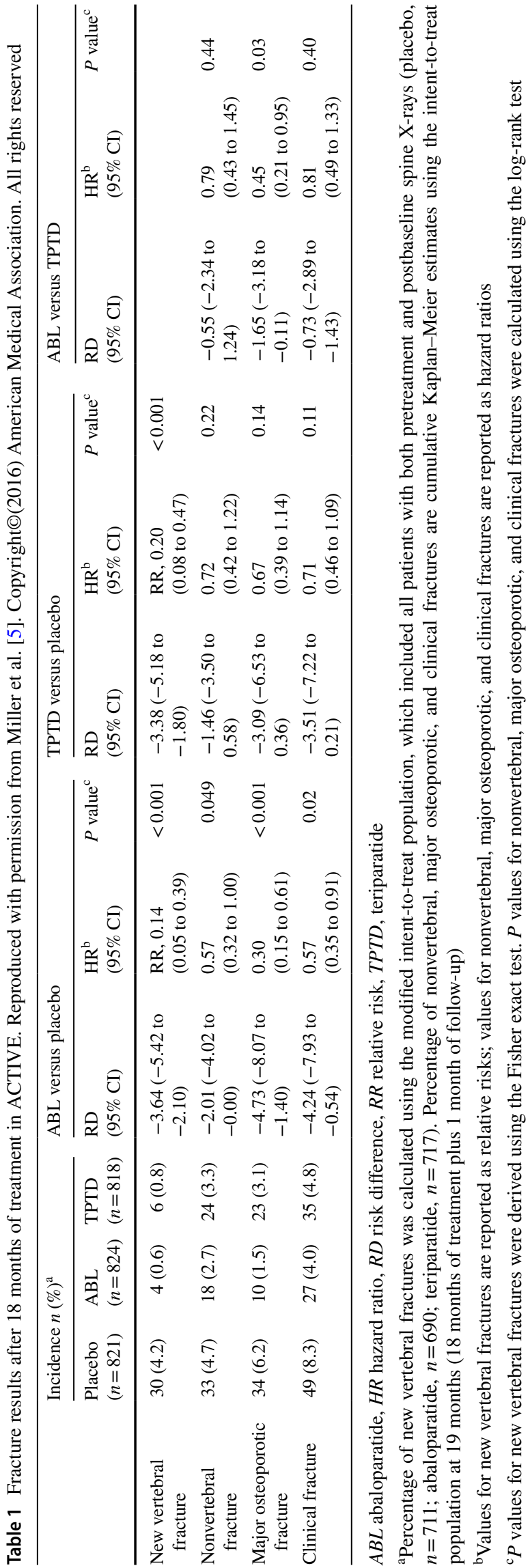

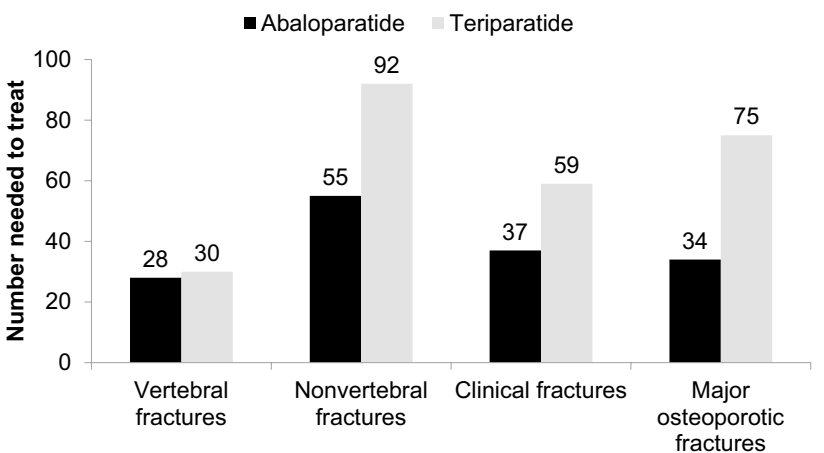

Fig. 1 Number needed to treat, by fracture type, after 18 months of treatment with abaloparatide or teriparatide in ACTIVE

ABL NNT ranging from $37 \%$ less for clinical fracture (37 for ABL vs. 59 for TPTD) to $55 \%$ less for major osteoporotic fracture (34 for ABL vs. 75 for TPTD).

The observed treatment differences between $\mathrm{ABL}$ and TPTD may be explained at least in part by the underlying physiological differences, and subsequent different binding profiles, of TPTD, a PTH analog, and ABL, a PTHrP analog $[2,17]$. PTH binds with greater affinity and stability to the $\mathrm{R}^{0}$ conformation of the PTH1R than does PTHrP. Conversely, PTHrP has greater binding affinity for the RG conformation of the receptor, which results in more transient receptor signaling. Thus, despite PTH and PTHrP analogs binding to the same PTH1R, the different signaling pathways they affect appear to induce different biological responses [2].

The incidence of new morphometric vertebral fractures in the placebo group in ACTIVE was $4.2 \%$, which was lower than the IRs of new vertebral fractures among placebo groups from several other trials of drugs to treat postmenopausal osteoporosis. Contemporary ethical concerns around assigning patients with severe disease to a placebo group led the ACTIVE investigators to enroll patients with lower risk of fractures than in many earlier clinical trials of other antifracture medications. To help understand the potential effects of $\mathrm{ABL}$ in populations that may have greater risk of new vertebral fracture than the $4.2 \%$ placebo IR observed in ACTIVE, we explored the potential effectiveness of ABL in historical trial populations, including those with higher placebo IRs than that in ACTIVE. This investigation assumed that the RRR observed in ACTIVE would be maintained in study populations with varying baseline risk and who were treated for periods longer than the 18 months of ABL treatment in ACTIVE. These assumptions were based on the apparent consistency of effect associated with ABL treatment over time $[5,18,19]$ and across patient risk subgroups $[14,20]$.

We therefore calculated projected NNTs for ABL by applying the $86 \%$ RRR evident in ACTIVE to three 
Fig. 2 Projected number needed to treat with ABL based on incidence rates reported in populations with varying placebo-group incidence rates of new vertebral fracture. NNTs included for denosumab and for alendronate are as reported in FREEDOM [10], FIT-1 [11], and FIT-2 [12]. $A B L$ abaloparatide, $I R$ incidence rate, $N N T$ number needed to treat, $P B O$ placebo.

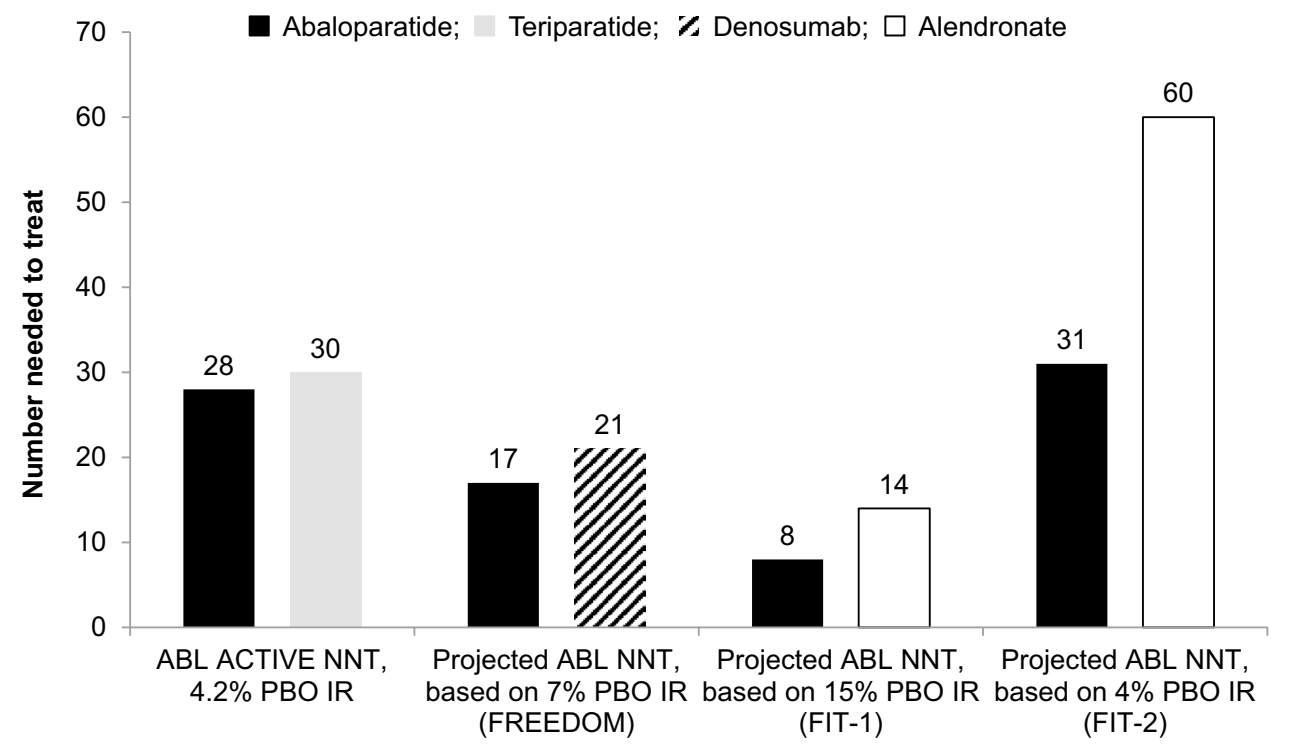

period and the 24-month alendronate monotherapy treatment period of ACTIVExtend [5, 18, 19], we assumed a similar consistent treatment effect across trials of varying study duration. Additionally, since the effects of ABL on fracture risk reduction appear to be independent of baseline risk factors and FRAX® fracture probability [14, 20], we assumed a consistent effect across trials with patients of varying baseline risk compared with ACTIVE. Despite these assumptions, however, results of the historical comparisons should be interpreted with caution.

\section{Conclusions}

After 18 months of treatment in ACTIVE, the NNT for ABL was similar to that for TPTD for new vertebral fractures and lower than that for TPTD for nonvertebral, clinical, and major osteoporotic fractures. In historical populations with higher placebo IRs of vertebral fractures than were enrolled in ACTIVE, the projected NNT for ABL was lower than the calculated NNT using the ACTIVE trial population and was similar to the NNT for TPTD in the historical trial population with a similarly higher placebo IR. While such comparisons must be interpreted with caution, the NNT calculated for ABL was consistently lower than that for the active treatment arms of each historical trial analyzed, regardless of placebo IR. These data are useful for further evaluating ABL for the treatment of osteoporosis in postmenopausal women.

Acknowledgements ACTIVE and this analysis were funded by Radius Health, Inc., Waltham, MA. Data in this paper were presented as a poster at the Annual Meeting of the American Society for Bone and Mineral Research, September 19, 2016; poster ID \#MO0280 and at the World Congress on Osteoporosis, March 25, 2017; oral presentation \#OC18. Medical writing support was provided by Gregory across multiple timepoints during the 18 -month treatment 
Bezkorovainy, MA, Adelphi Communications, New York and was funded by Radius Health, Inc.

Author Contributions J-YR takes responsibility for the overall content and is the guarantor for the paper. All authors had access to the data sources reported in the study. MH was responsible for statistical analysis of the data. GH and GW participated in study design. All authors revised the paper critically for intellectual content and approved the final version for submission.

\section{Compliance with Ethical Standards}

Conflict of interest Jean-Yves Reginster reports consulting fees or paid advisory boards from IBSA-Genevrier, Mylan, Pierre Fabre, and Radius Health, Inc.; lecture fees when speaking at the invitation of the following sponsors: IBSA-Genevrier, Mylan, CNIEL, Dairy Research Council (DRC); and grant support from industry (all through his institution) from: IBSA-Genevrier, Mylan, CNIEL, and Radius Health, Inc. Gary Hattersley, Gregory C. Williams, Ming-yi Hu, and Lorraine A. Fitzpatrick are employees of Radius Health, Inc. and own stock in Radius Health, Inc. E. Michael Lewiecki has received institutional grant/research support from Amgen, PFEnex, and Mereo; has served on scientific advisory boards for Amgen, Radius Health, Inc., Shire, Alexion, Ultragenyx, and Sandoz; and serves on the speakers' bureau for Shire, Alexion, and Radius Health, Inc.

Research Involving Human Participants and Informed Consent Participants in the phase 3 ACTIVE study provided written informed consent, and the protocol was approved by the respective institutional review boards.

Open Access This article is distributed under the terms of the Creative Commons Attribution 4.0 International License (http://creativeco mmons.org/licenses/by/4.0/), which permits unrestricted use, distribution, and reproduction in any medium, provided you give appropriate credit to the original author(s) and the source, provide a link to the Creative Commons license, and indicate if changes were made.

\section{References}

1. Hattersley G, Dean T, Corbin BA, Bahar H, Gardella TJ (2016) Binding selectivity of abaloparatide for PTH-type-1-receptor conformations and effects on downstream signaling. Endocrinology 157(1):141-149

2. Esbrit P, Herrera S, Portal-Núñez S, Nogués X, Díez-Pérez A (2016) Parathyroid hormone-related protein analogs as osteoporosis therapies. Calcif Tissue Int 98(4):359-369

3. Bahar H, Gallacher K, Downall J, Nelson CA, Shomali M, Hattersley G (2016) Six weeks of daily abaloparatide treatment increased vertebral and femoral bone mineral density, microarchitecture and strength in ovariectomized osteopenic rats. Calcif Tissue Int 99(5):489-499

4. Leder BZ, O'Dea LS, Zanchetta JR, Kumar P, Banks K, McKay K, Lyttle CR, Hattersley G (2015) Effects of abaloparatide, a human parathyroid hormone-related peptide analog, on bone mineral density in postmenopausal women with osteoporosis. J Clin Endocrinol Metab 100(2):697-706

5. Miller PD, Hattersley G, Riis BJ, Williams GC, Lau E, Russo LA, Alexandersen P, Zerbini CA, Hu MY, Harris AG, Fitzpatrick LA, Cosman F, Christiansen C, for the ACTIVE Study Investigators (2016) Effect of abaloparatide vs placebo on new vertebral fractures in postmenopausal women with osteoporosis: a randomized clinical trial. JAMA 316(7):722-733

6. Varela A, Chouinard L, Lesage E, Smith SY, Hattersley G (2017) One year of abaloparatide, a selective activator of the PTH1 receptor, increased bone formation and bone mass in osteopenic ovariectomized rats without increasing bone resorption. J Bone Miner Res 32(1):24-33

7. Varela A, Chouinard L, Lesage E, Guldberg R, Smith SY, Kostenuik PJ, Hattersley G (2017) One year of abaloparatide, a selective peptide activator of the PTH1 receptor, increased bone mass and strength in ovariectomized rats. Bone 95:143-150

8. Moreira CA, Fitzpatrick LA, Wang Y, Recker RR (2017) Effects of abaloparatide-SC (BA058) on bone histology and histomorphometry: the ACTIVE phase 3 trial. Bone 97:314-319

9. Laupacis A, Sackett DL, Roberts RS (1988) An assessment of clinically useful measures of the consequences of treatment. N Engl J Med 318(26):1728-1733

10. Cummings SR, San Martin J, McClung MR, Siris ES, Eastell R, Reid IR, Delmas P, Zoog HB, Austin M, Wang A, Kutilek S, Adami S, Zanchetta J, Libanati C, Siddhanti S, Christiansen C, for the FREEDOM Trial (2009) Denosumab for prevention of fractures in postmenopausal women with osteoporosis. N Engl J Med 361(8):756-765

11. Black DM, Cummings SR, Karpf DB, Cauley JA, Thompson DE, Nevitt MC, Bauer DC, Genant HK, Haskell WL, Marcus R, Ott SM, Torner JC, Quandt SA, Reiss TF, Ensrud KE, for the Fracture Intervention Trial Research Group (1996) Randomised trial of effect of alendronate on risk of fracture in women with existing vertebral fractures. Lancet 348(9041):1535-1541

12. Cummings SR, Black DM, Thompson DE, Applegate WB, Barrett-Connor E, Musliner TA, Palermo L, Prineas R, Rubin SM, Scott JC, Vogt T, Wallace R, Yates AJ, LaCroix AZ, for the Fracture Intervention Trial Research Group (1998) Effect of alendronate on risk of fracture in women with low bone density but without vertebral fractures: results from the Fracture Intervention Trial. JAMA 280(24):2077-2082

13. Cranney A, Guyatt G, Griffith L, Wells G, Tugwell P, Rosen C, Osteoporosis Methodology Group and The Osteoporosis Research Advisory Group (2002) Meta-analyses of therapies for postmenopausal osteoporosis. IX: summary of meta-analyses of therapies for postmenopausal osteoporosis. Endocr Rev 23(4):570-578

14. Cosman F, Hattersley G, Hu MY, Williams GC, Fitzpatrick LA, Black DM (2017) Effects of abaloparatide-SC on fractures and bone mineral density in subgroups of postmenopausal women with osteoporosis and varying baseline risk factors. J Bone Miner Res 32(1):17-23

15. Gielen $E$, Bergmann $P$, Bruyère $O$, Cavalier $E$, Delanaye $P$, Goemaere S, Kaufman JM, Locquet M, Reginster JY, Rozenberg S, Vandenbroucke AM, Body JJ (2017) Osteoporosis in frail patients: a consensus paper of the Belgian Bone Club. Calcif Tissue Int 101(2):111-131

16. Kanis JA, Rizzoli R, Cooper C, Reginster JY (2014) Challenges for the development of bone-forming agents in Europe. Calcif Tissue Int 94(5):469-473

17. Ralston SH, Rizzoli R (2016) New targets and new treatments: recent advances in the treatment of musculoskeletal disease. Calcif Tissue Int 98(4):317-318

18. Cosman F, Miller PD, Williams GC, Hattersley G, Hu MY, Valter I, Fitzpatrick LA, Riis BJ, Christiansen C, Bilezikian JP, Black D (2017) Eighteen months of treatment with subcutaneous abaloparatide followed by 6 months of treatment with alendronate in postmenopausal women with osteoporosis: results of the ACTIVExtend trial. Mayo Clin Proc 92(2):200-210

19. Bone HG, Cosman F, Miller PD, Williams GC, Hattersley G, Hu MY, Fitzpatrick LA, Mitlak B, Papapoulos S, Rizzoli R, Dore 
RK, Bilezikian JP, Saag KG (2018) ACTIVExtend: 24 months of alendronate after 18 months of abaloparatide or placebo for postmenopausal osteoporosis. J Clin Endocrinol Metab. https:// doi.org/10.1210/jc.2018-00163

20. McCloskey EV, Johansson H, Oden A, Harvey NC, Jiang H, Modin S, Fitzpatrick L, Kanis JA (2017) The effect of abaloparatide-SC on fracture risk is independent of baseline FRAX fracture probability: a post hoc analysis of the ACTIVE study. J Bone Miner Res 32(8):1625-1631

21. Neer RM, Arnaud CD, Zanchetta JR, Prince R, Gaich GA, Reginster JY, Hodsman AB, Eriksen EF, Ish-Shalom S, Genant HK,
Wang O, Mitlak BH (2001) Effect of parathyroid hormone (1-34) on fractures and bone mineral density in postmenopausal women with osteoporosis. N Engl J Med 344(19):1434-1441

22. Lewiecki EM, Miller PD, Harris ST, Bauer DC, Davison KS, Dian L, Hanley DA, McClung MR, Yuen CK, Kendler DL (2014) Understanding and communicating the benefits and risks of denosumab, raloxifene, and teriparatide for the treatment of osteoporosis. J Clin Densitom 17(4):490-495 